\title{
DIECISIETE AÑOS DESPUÉS
}

Julián Meza*

Durante el llamado período de la guerra fría (bastante caliente en las periferias del Este y del Oeste: revueltas y represiones en Hungría, Polonia y Checoslovaquia; guerras de independencia en África del Norte y en el África negra; guerrillas y golpes de Estado en América Latina; y disputas por el control de Corea, Vietnam, Camboya y Laos en Asia, que fueron países convertidos por la URSS y los USA en laboratorios donde ensayaban su arsenal militar), el sovietismo sí representaba una amenaza real para Occidente. La URSS no sólo disponía de un vasto arsenal nuclear, sino que contaba con poderosas filiales y numerosos adeptos en Occidente. Los partidos comunistas en países como Francia e Italia eran muy poderosos; muchos intelectuales eran compañeros de viaje de los comunistas y en numerosas regiones de Asia, África y América Latina los supuestos logros económicos y sociales de la URSS eran un atractivo porque se trataba de continentes saqueados y humillados por el gran capital, cuya sede eran los USA.

Con el estrepitoso derrumbe del bloque soviético muchas cosas cambiaron. No pocos de sus partidarios se dieron cuenta, sólo entonces, de que el hundimiento de la URSS se debía a que en realidad sólo era una potencia policiaca y militar, pero que carecía de una economía civil (Castoriadis), debido a lo cual los habitantes de ese imperio padecían verdaderas hambrunas. La derrota de la URSS no fue, por lo tanto, consecuencia de la defensa de los derechos humanos en ese inmenso

* Departamento Académico de Estudios Generales, ITAM. 
territorio y en sus países satélites, patrocinada por los Estados Unidos y el Vaticano, sino de sus propios errores. La Unión Soviética no pudo hacer nada cuando sus satélites se rebelaron y liquidaron el totalitarismo de muy diversas maneras, que fueron desde el asesinato de un tirano como Ceausescu en Rumania hasta le revolución de terciopelo en Checoslovaquia, que se caracterizó por el hecho de que los checos no dispararon un solo tiro para acabar con el totalitarismo, debido tal vez a que uno de los grandes opositores al régimen comunista fue el futuro presidente Vaclav Havel, que al igual que su predecesor republicano, el presidente Mazarik, fue un poeta.

Pero quizá una de las consecuencias más importantes del proceso de desintegración de la URSS esté en el hecho de que a partir de ese momento Occidente, y en particular los USA, se quedaran sin un enemigo al que declarar responsable del malestar en el mundo. Desaparecida la URSS, los USA no encontraron a quién culpabilizar de sus propios errores, enfatizados por el liberalismo a ultranza que se puso en marcha desde el momento en que la señora Tatcher optó por este camino. Luego, cuando el espejismo de la URSS se esfumó, los nuevos liberales decidieron suprimir todo aquello que el estado de bienestar había edificado para contrarrestar el atractivo de la propaganda soviética. Paulatinamente decidieron suprimirlo, sobre todo en la periferia de Occidente y en particular en América Latina. En la antigua URSS y en sus países satélites son los antiguos dirigentes del mundo soviético los que se han encargado de suprimir los beneficios sociales de los que disfrutaba la población, pese al totalitarismo. Una de las paradojas del régimen soviético es que pese a la tiranía, la educación (no obstante ser sesgada porque era ideológica), la cultura (que atentaba contra la literatura, la poesía y las artes plásticas, pero favorecía la música, el ballet y la ópera), la ciencia (militar) y el deporte eran prioridades. Hoy, un profesor universitario en Rusia percibe como salario el equivalente a 20 dólares mensuales y un médico especializado 40, mientras que los miembros de la antigua nomenclatura son millonarios. La idea de que la China actual es una amenaza para Occidente es por lo menos inocente. Son los miembros del Partido Comunista Chino los 
que se están convirtiendo en millonarios, mientras que los trabajadores son peor pagados que los mexicanos, y de ahí que las maquiladoras emigren de México y se vayan a China. Si el salario de un trabajador mexicano es poco más que infame, el de los trabajadores chinos es cercano a las prácticas esclavistas.

Derrumbado el mundo soviético, Occidente, y en particular los USA, se quedaron sin enemigos. Todo cambió con el ataque a las torres gemelas de Nueva York el 11 de septiembre de 2001, que inaugura el siglo XXI, con mayor rapidez que el siglo XX, que empezó con la guerra del 14. Hay comentaristas que suscriben el discurso oficial de la administración norteamericana: fue obra del fundamentalismo islámico, financiado por un hermano de la familia que es socia del presidente Bush: Bin Laden. Otros, entre los que se cuentan varios intelectuales norteamericanos, porque los europeos están en franco proceso de decadencia, como el señor André Glucksman, que apoya a Bush, Aznar y Berlusconi, dudan de la versión oficial contra el atentado a las torres gemelas. Ciertamente, un fundamentalista es capaz de suicidarse por sus supuestas creencias, pero si le pagan por hacerlo dando muerte, al mismo tiempo, a miles de infieles, lo hará con mayor regocijo. ¿Quién les pago a los suicidas que derribaron las torres gemelas? Es algo que no se sabe, y seguramente nunca se sabrá. Pero lo que sí se sabe es que a continuación el presidente Bush, iluminado por su Dios, decidió emprender una cruzada que empezó en Afganistán, cuyo objetivo fundamental nunca se logró: dar caza a Bin Laden. En cambio, sí obtuvo, en parte, el control de un territorio fundamental para el transporte del gas natural que escasamente se produce en los USA. Vino a continuación la invasión de Irak porque, supuestamente, ese país gobernado por un sátrapa como Sadam Hussein, producía armas de destrucción masiva. Aun cuando se demostró, antes y después de la invasión, que esto no era cierto, los USA invadieron Irak, y pese a que sus costos en vidas humanas norteamericanas no alcancen las proporciones a las que llegaron en Vietnam no son despreciables: más de dos mil soldados de los USA han muerto ahí. 
Una de las cosas curiosas en esta guerra democratizadora de Irak es que los gobernantes norteamericanos no piensen lo mismo, por ejemplo, a propósito de Arabia Saudita, gobernada por déspotas comparables con Hussein. ¿Por qué no hacer una guerra para democratizar este país? Obviamente, porque se trata de un aliado cuyos gobernantes son socios de los norteamericanos. Lo mismo se puede decir de países como Kuwait, defendido por los USA cuando fue atacado por Irak. Pero esta guerra por el control del petróleo iraquí no acaba aquí. Las principales exportaciones petroleras de Irak eran a Francia y a Alemania, y esto evidencia que el enemigo principal de los USA es la Unión Europea. Lamentablemente, para los USA, países como Francia cada vez dependen menos del petróleo para producir, por ejemplo, electricidad. Tras el masivo apagón en Italia, cuya electricidad depende del petróleo, pese a sus desacuerdos con los dirigentes franceses, Berlusconi decidió pedir auxilio a Francia para producir electricidad mediante energía atómica.

En teoría, los gobernantes norteamericanos han emprendido una cruzada contra el fundamentalismo islámico, al que han declarado su enemigo principal, pero en realidad esta cruzada va dirigida contra la Unión Europea, que es la única que puede competir con ellos. Los próximos objetivos militares de los USA pueden estar en Medio Oriente, a causa del petróleo, como ocurre en el caso de Irán, pero se pueden extender a Asia, en donde el objetivo puede ser Corea del Norte, pero el verdadero enemigo de los USA es la Unión Europea, pues es la única que en realidad puede competir comercial, económica y financieramente con ellos.

Por supuesto que Europa no es una unidad. O es una unidad relativa, saboteada, en primer término, por Inglaterra, que actúa como quinta columna en el continente, dado que se trata de un protectorado al servicio de los USA. En segundo lugar por un gobernante como Berlusconi, al que le interesan más sus negocios que el país. Y en tercer término por partidos políticos como el PP en España, que por lo pronto no tiene la dirección del país, pero que nada impide descartar su regreso al poder, dadas las veleidades del moderno electorado, que 
recuerdan las de la plebe romana, puesto que aún no escapa del todo a su pasado franquista, todavía representado por los delfines de la dictadura: Aznar y Rajoy.

Uno de los principales problemas de las democracias modernas son los electores, que parecen no haber aprendido nada de los años anteriores a la segunda guerra mundial, cuando los alemanes votaron por Hitler. Hoy se vota por Le Pen, o por declarados fascistas en Austria y Holanda. Sospechosamente, el electorado norteamericano reelige ¡a Bush! No dudo que el PP vuelva al poder muy pronto, aunque su principal artífice, Fraga, sea en ex funcionario franquista y el vetusto electorado español demuestre, una vez más, que carece de memoria, o que añora los malhadados tiempos de Isabel la católica y la inquisición. Los rusos son gobernados por un antiguo funcionario de la KGB. Los chinos será los esclavos de los actuales miembros del comité central del Partido Comunista de China. Es obvio que las alternativas en América Latina no son Chávez, Lula o Evo, cuyo nombre, masculinizado, evoca un imposible paraíso. ¿Qué ocurre en México en el período actual? La población se prepara para elegir de los males el menor, aun cuando los males no se hallen definidos con claridad. A uno de los candidatos, el perredista, se le acusa de populismo, pero no lo es menos que el actual presidente, al que se suponía era el emblemático personaje del cambio, que en realidad no sólo no ha cambiado nada, sino que sus prácticas políticas y económicas lo vinculan con el autoritarismo, el patrimonialismo y el paternalismo del pasado. Pese al panismo, el priísmo prevalece. Sin lugar a dudas, la figura presidencial se desdibujó, pero se incrementó el poder de la primera dama, que por sus prácticas no está lejos de ser la última. Disminuyó el poder del partido único, pero el corporativismo, sobre todo el sindical, está intacto y la corrupción prevalece. El candidato panista a la presidencia es una triste réplica del señor Abascal, que ha convertido la secretaría de gobernación en un púlpito, desde donde predica sermones fundamentalistas. El tercero en discordia, cabeza visible del irredento PRI, es algo más que un delincuente. Frente a este panorama el elector se prepara para votar por el menor de los males. Mi pregunta al electorado es muy sencilla: 
¿Cuál es el menor de los males? Al igual que decía Shakespeare en Hamlet: "Algo apesta en Dinamarca", se puede decir que algo apesta en el mundo actual, y en particular en México. Es posible oponer a esto los mejores deseos humanistas, literarios, poéticos, filosóficos, pero nada va a cambiar porque la naturaleza humana no ha variado un ápice desde hace treinta mil años. El progreso, que es exclusivamente científico y tecnológico, consiste en la capacidad del hombre para ser cada vez más eficazmente destructivo. Tal vez me equivoque, pero nada indica que los valores éticos puedan derrotar la ausencia de valores, como lo demuestra Stephan Zweig en La Europa de ayer, en donde evoca un mundo en donde, pese a todo, prevalecían el honor, la dignidad y, a fin de cuentas, la sabiduría, y no el conocimiento, que hoy se ha reducido a la información, como lo decía ya a principios del siglo XX T. S. Elliot.

México, 2006. 